\title{
Triple Oxygen Isotope Measurements by Multi-Collector Large-Geometry Secondary Ion Mass Spectrometry
}

\author{
PAULA PERES $^{1}$, NORDINE BOUDEN ${ }^{2}$, JOHAN \\ VILLENEUVE $^{3}$, YVES MARROCCHI ${ }^{4}$, ETIENNE \\ DELOULE $^{3}$, EVELYN FÜRI ${ }^{5}$, ANDREY GURENKO ${ }^{6}$, \\ LAURETTE PIANI $^{2}$, EMILIE THOMASSOT ${ }^{2}$ AND FIRMINO \\ FERNANDES ${ }^{1}$ \\ ${ }^{1}$ CAMECA \\ ${ }^{2} \mathrm{CRPG}$ \\ ${ }^{3}$ Université de Lorraine, CNRS, CRPG \\ ${ }^{4} \mathrm{CRPG}, \mathrm{CNRS}-$ Université Lorraine \\ ${ }^{5}$ Université de Lorraine/CNRS \\ ${ }^{6}$ Université de Lorraine \\ Presenting Author: paula.peres@ametek.com
}

Secondary ion mass spectrometry (SIMS) is a powerful technique for in situ triple oxygen isotope measurements that has been used for more than 30 years. Since pioneering works performed on small-radius ion microprobes in the mid-80s, tremendous progress has been made in terms of analytical precision, spatial resolution and analysis duration. In this respect, the emergence in the mid-90s of a large-geometry ion probe equipped with a multicollector system (LG-SIMS) was a game changer. Further developments were implemented on CAMECA LG-SIMS since then; e.g. stability of the electronics, enhanced transmission of secondary ions, automatic centering of the secondary ion beam, enhanced control of the magnetic field.

This talk aims to first describe the different classical settings used for triple oxygen isotope measurements by LG-SIMS, then emphasizes recent technical developments that open an innovative path for this type of analyses. This new analytical method, based on a low noise Faraday Cup detector equipped with a $10^{12} \Omega$ preamplifier board, allows nowadays to routinely measure oxygen isotopic ratios $\left({ }^{18} \mathrm{O} /{ }^{16} \mathrm{O}\right.$ and $\left.{ }^{17} \mathrm{O} /{ }^{16} \mathrm{O}\right)$ in various matrices with a precision (internal error and reproducibility) better than $0.5 \%$ o $(2 \sigma)$, a spatial resolution smaller than $10 \mu \mathrm{m}$ and in a few minutes per analysis.

Finally, recent examples of application of this state-of-the-art LG-SIMS method in planetary sciences will be shown. 